\title{
Solution and Solid-State Nuclear Magnetic Resonance Structural Investigations of the Antimicrobial Designer Peptide GL13K in ${ }_{3}$ Membranes
}

\author{
${ }_{4}$ Nicole Harmouche, ${ }^{\dagger}$ Christopher Aisenbrey, ${ }^{\dagger}$ Fernando Porcelli, $^{\ddagger}$ Youlin Xia, $^{\S}$ Sarah E. D. Nelson, ${ }^{\S}$ \\ ${ }_{5} \mathrm{Xi}$ Chen, ${ }_{6}$ Jesus Raya, ${ }^{\dagger}$ Louic Vermeer, ${ }^{\dagger}$ (๑ Conrado Aparicio, ${ }^{\| \odot ~ G i a n l u i g i ~ V e g l i a, ~}{ }^{\S}$ Sven-Ulrik Gorr, ${ }^{\perp}$ \\ 6 and Burkhard Bechinger*, ${ }^{\dagger}$ \\ 7 'Université de Strasbourg/CNRS, UMR7177, Institut de Chimie, 1, rue Blaise Pascal, 67070 Strasbourg, France \\ 8 'DIBAF-University of Tuscia-Viterbo, Largo dell’Universita', Blocco D, 01100 Viterbo, Italy \\ $9{ }^{8}$ Department of Biochemistry, Molecular Biology \& Biophysics, University of Minnesota, 321 Church Street Southeast, Minneapolis, \\ 10 Minnesota 55455, United States \\ 11 "Minnesota Dental Research Center for Biomaterials and Biomechanics and Department of Restorative Sciences, University of \\ 12 Minnesota School of Dentistry, 515 Delaware Street Southeast, Minneapolis, Minnesota 55455, United States \\ ${ }_{13}{ }^{\perp}$ Department of Diagnostic and Biological Sciences, University of Minnesota School of Dentistry, 515 Delaware Street Southeast, \\ 14 Minneapolis, Minnesota 55455, United States
}

16 ABSTRACT: The antimicrobial peptide GL13K encompasses

$17 \quad 13$ amino acid residues and has been designed and optimized

18 from the salivary protein BPIFA2 to exhibit potent

19 bacteriocidal and anti-biofilm activity against Gram-negative

20 and Gram-positive bacteria as well as anti-lipopolysaccharide

21 activity in vitro and in vivo. Here, the peptide was analyzed in a

22 variety of membrane environments by circular dichroism

23 spectroscopy and by high-resolution multidimensional solution

24 nuclear magnetic resonance (NMR) spectroscopy. Whereas in
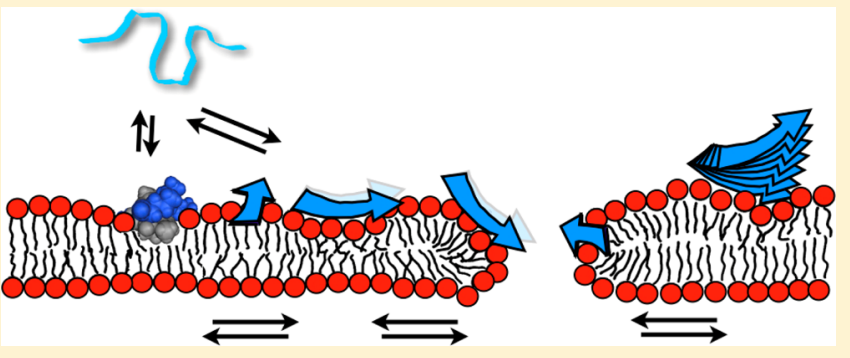

the absence of membranes a random coil conformation

predominates, the peptide adopts a helical structure from residue 5 to 11 in the presence of dodecylphosphocholine micelles. In contrast, a predominantly $\beta$-sheet structure was observed in the presence of lipid bilayers carrying negatively charged phospholipids. Whereas ${ }^{15} \mathrm{~N}$ solid-state NMR spectra are indicative of a partial alignment of the peptide ${ }^{15} \mathrm{~N}-{ }^{1} \mathrm{H}$ vector along the membrane surface, ${ }^{2} \mathrm{H}$ and ${ }^{31} \mathrm{P}$ solid-state NMR spectra indicate that in this configuration the peptide exhibits pronounced disordering activities on the phospholipid membrane, which is possibly related to antimicrobial action. GL13K, thus, undergoes a number of conformational transitions, including a random coil state in solution, a helical structure upon dilution at the surface of zwitterionic membranes, and $\beta$-sheet conformations at high peptide:lipid ratios.

${ }_{4}^{33} \mathrm{~A}$ ntimicrobial peptides and proteins (AMPs) are found in vertebrates, invertebrates, plants, and bacteria, and several 35 of these naturally occurring AMPs have inspired the design of 36 novel AMPs. ${ }^{1,2}$ Synthetic peptide design aims to optimize 37 strong antibacterial activity while avoiding bacterial resistance 38 or mammalian toxicity. AMP sequences are highly diverse, but 39 certain principles of their design have emerged. Thus, short 40 AMPs appear to require a balance of charged ( $\mathrm{R}$ and $\mathrm{K}$ ) and 41 hydrophobic amino acids (I, V, F, Y, and W). ${ }^{3}$ We have 42 designed the peptide GL13K by analysis of the salivary protein 43 BPIFA2 (BPI-fold family A member 2; previously named 44 parotid secretory protein, PSP, SPLUNC2, and C20orf70), a 45 potential host-defense protein. The predicted structure of 46 BPIFA2 was compared with the known structures of related $47 \mathrm{BPI}$ proteins ${ }^{4}$ and the location of AMPs within the sequences 48 of these proteins. $^{5}$ An initial peptide, GL13NH2
(BPIFA2 $\left.2_{141-153}\right)$, caused bacterial agglutination but did not 49 exhibit bactericidal activity. ${ }^{6}$ The distribution of cationic and 50 hydrophobic residues was rebalanced by substituting charged 51 residues with Lys residues, resulting in the peptide GL13K, 52 which is bactericidal to Gram-negative and Gram-positive 53 bacteria and their biofilms. ${ }^{6,7}$ Both GL13NH2 and GL13K also 54 exhibit anti-lipopolysaccharide activity in vitro and in vivo. ${ }^{6}{ }_{55}$

Initial membrane interaction studies have shown that GL13K 56 is highly selective for anionic bacterial model membranes 57 (DOPG) compared to zwitterionic (neutral) eukaryotic model 58 membranes (DOPC). In the presence of DOPC, the peptide 59 exhibits a random coil conformation in circular dichroism (CD) 60

Received: June 2, 2017

Revised: July 6, 2017

Published: July 12, 2017 
61 spectroscopic investigations and adopts a $\beta$-sheet structure in 62 the presence of DOPG. ${ }^{8}$ Thus, as with other cationic 63 amphipathic peptides, the extent of association with overall 64 neutral membranes is probably too low to be detected by 65 optical spectroscopy, which, due to light scattering, is limited to 66 dilute solutions of small vesicles.

67 Here we use multidimensional solution NMR spectroscopy 68 to investigate the high-resolution structure of GL13K in the 69 presence of dodecylphosphocholine (DPC) micelles, thus, 70 representing its structure when it is associated with zwitterionic 71 membranes at low P:L ratios (on average fewer than one 72 peptide is associated with each micelle). Furthermore, a 73 bacterial membrane was mimicked by 3:1 (molar ratio) 74 POPE/POPG model bilayers. The peptide's secondary 75 structure preference at this intermediate membrane lipid 76 composition with only $25 \mathrm{~mol} \%$ negatively charged lipids 77 was first determined by $\mathrm{CD}$ spectroscopy. Thereafter, the 78 peptide topology and its interactions with lipids were 79 investigated by reconstituting GL13K, labeled with ${ }^{2} \mathrm{H}$ and ${ }_{80}{ }^{15} \mathrm{~N}$ at specific sites, into bilayers aligned along planar glass 81 plates or in bicelles that spontaneously align in the magnetic 82 field of the NMR spectrometer, and measurement of the 83 corresponding solid-state NMR spectra. Finally, the effect of 84 the peptide on membrane packing was investigated by ${ }^{2} \mathrm{H}$ solid85 state NMR of fatty acyl chain deuterated lipids. In this manner, 86 a more comprehensive view of the interactions of GL13K with 87 membranes is obtained covering low and high peptide:lipid 88 ratios as they occur with overall neutral, zwitterionic, and 89 negatively charged bacterial membranes.

\section{MATERIALS AND METHODS}

91 Materials. Amino acid derivatives and other reagents for 92 peptide synthesis were from Novabiochem-Merck (Darmstadt, 93 Germany). All lipids were purchased from Avanti Polar Lipids 94 (Alabaster, AL). Water (HPLC grade) and deuterium-depleted 95 water were from Sigma (St. Quentin Fallavier, France). 96 Deuterated dodecylphosphocholine was purchased from Cam97 bridge Isotope Laboratories (Andover, MA).

98 Peptide Synthesis. The GL13K peptide (GKIIKLKASL$99 \mathrm{KLL}^{-\mathrm{NH}_{2}}$ ) was obtained by solid phase peptide synthesis using 100 a Millipore 9050 automated peptide synthesizer and Fmoc (9101 fluorenylmethyloxycarbonyl) chemistry. The peptide was 102 purified by semipreparative HPLC as described previously for 103 other antimicrobial peptides. ${ }^{9}$ The underlined leucine 6 and the 104 bold alanine 8 positions were labeled with ${ }^{15} \mathrm{~N}$ and ${ }^{2} \mathrm{H}_{3}$, 105 respectively, by incorporation of the isotopically labeled fmoc 106 precursors (Euriso-top, Paris, France, or Isotec Sigma-Aldrich, 107 St. Quentin Fallavier, France). The identity and high purity of 108 the product $(>90 \%)$ were confirmed by HPLC, MALDI mass 109 spectrometry, and NMR spectroscopy. After lyophilization, the 110 TFA counterions were exchanged in $5 \%(\mathrm{v} / \mathrm{v})$ acetate. The 111 randomized peptide GL13K-R1 with the sequence IGIKLLK112 SKLKAL-NH2 was obtained from AAPPTec (Louisville, KY). 113 Micellar Sample Preparation and Solution NMR 114 Spectroscopy. The lyophilized peptide was dissolved to a 115 final concentration of $1.9 \mathrm{mM}$ in an aqueous solution $(10 \%$ $116 \mathrm{D}_{2} \mathrm{O}$ and $90 \% \mathrm{H}_{2} \mathrm{O}$ ) containing $186 \mathrm{mM}$ perdeuterated DPC 117 (Cambridge Isotope Laboratories) and $10 \mathrm{mM}$ phosphate 118 buffer at $\mathrm{pH}$ 5. All the NMR experiments were performed at $119298 \mathrm{~K}$ on a Bruker $700 \mathrm{MHz}$ spectrometer (Bruker Biospin, 120 Billerica, MA). The homonuclear two-dimensional (2D) 121 TOCSY $^{10}(70 \mathrm{~ms})$ and $2 \mathrm{D} \mathrm{NOESY}{ }^{11}$ (100-250 ms mixing 122 time) experiments were performed in phase-sensitive mode using time-proportional phase incrementation. A WATER- 123 GATE pulse sequence ${ }^{12}$ was used for solvent suppression. 124 During the isotropic mixing time, a DIPSI-2 pulse sequence ${ }^{13} 125$ was used in the TOCSY experiments. In all experiments, the 126 spectral width was $8000 \mathrm{~Hz}$ in both dimensions. 2D data were 127 zero filled to 4096 points in the direct dimension and to 1024128 points in the indirect dimension and then processed using a 129 sine-bell squared window function shifted between $60^{\circ}$ and $90^{\circ} \quad 130$ before Fourier transformation. For baseline correction, a sixth- 131 order polynomial function was used.

All the spectra were processed using NMRPipe, ${ }^{14}$ and the 133 data were analyzed using Sparky. ${ }^{15}$ The traditional resonance 134 assignment approach described by Wüthrich ${ }^{16}$ was applied. ${ }_{135}$

Structure Calculation. A total of 151 NOEs, including 70136 intra-residue and 81 inter-residue NOEs, were used for 137 structure calculation. NOE cross-peaks from 100-250 ms 138 mixing time ${ }^{1} \mathrm{H}-{ }^{1} \mathrm{H}$ NOESY experiments were integrated and 139 classified as strong, medium, and weak corresponding to 140 distance restraints of $1.8-2.9,1.8-3.6$, and $1.8-6.0 \AA$, 141 respectively. The GL13K structural ensemble was calculated 142 starting from the extended structure and minimized using a 143 hybrid simulating annealing (SA) protocol present in XPLOR- 144 NIH. ${ }^{17}$ One hundred conformers were generated at an initial 145 temperature of $1000 \mathrm{~K}$ with 50000 high-temperature steps and 146 6000 cooling steps. Structural refinement was performed by 147 introducing Lennard-Jones potentials and van der Waals and 148 electrostatic interactions using an initial temperature $\left(T_{\mathrm{i}}\right)$ of 149 $1000 \mathrm{~K}$ with 10000 cooling steps with a $5 \mathrm{fs}$ step size. The final 150 refinement of the structural ensemble was calculated at a $T_{\mathrm{i}}$ of 151 $600 \mathrm{~K}$ with 50000 cooling steps with a $1 \mathrm{fs}$ step size.

152

Circular Dichroism Spectroscopy. POPE/POPG (3:1 153 molar ratio) and POPC/POPS (3:1 molar ratio) lipids were 154 mixed in chloroform, dried under a stream of nitrogen gas, kept 155 under vacuum overnight, rehydrated with 5 or $10 \mathrm{mM}$ Tris- $\mathrm{HCl} 156$ at $\mathrm{pH} 7.4$, and subjected to three freeze/thaw cycles. Small 157 unilamellar vesicles (SUVs) were obtained after tip sonication 158 with a Bandelin Sonopuls HD 200 (Berlin, Germany) for $<1 \quad 159$ min. Circular dichroism (CD) spectra were recorded from 250160 to $190 \mathrm{~nm}$ (spectral resolution of $1 \mathrm{~nm}$, data pitch of $1 \mathrm{~nm}, 161$ scanning speed of $50 \mathrm{~nm} / \mathrm{min}$ ) using a Jasco J-810 or a J-815 162 spectropolarimeter (Jasco, Tokyo, Japan) and a quartz cell with 163 a $1.0 \mathrm{~mm}$ path length.

164

For lipid titration experiments, the samples containing 60165 $\mu \mathrm{M}$ GL13K peptide in $5 \mathrm{mM}$ Tris- $\mathrm{HCl}$ buffer ( $\mathrm{pH}$ 7.4) were 166 maintained at $37^{\circ} \mathrm{C}$ for titration with POPE/POPG SUVs and 167 at $25{ }^{\circ} \mathrm{C}$ for titration with POPC/POPS SUVs. A $13.6 \mathrm{mM} 168$ stock solution of SUVs was used for the peptide solution 169 titration at different peptide:lipid ratios. A total of nine spectra 170 were acquired and averaged for each condition. A mock 171 titration of lipids into $5 \mathrm{mM}$ Tris- $\mathrm{HCl}$ without peptide was used 172 to generate control curves, which were subtracted from the CD 173 spectra of peptide-containing samples. The resulting intensities 174 in millidegrees were converted to mean residue molar ellipticity 175 ( $\mathrm{MRE}=\theta / 10 n C l$, where $n$ is the number of peptide bonds, $C 176$ the concentration in molar, and $l$ the path length in 177 centimeters).

To obtain the pH-dependent circular dichroism (CD) 179 spectra of GL13K and GL13K-R1, the peptides were dissolved, 180 at a concentration of $0.1 \mathrm{mM}$, in a series of sodium borate 181 buffers at $\mathrm{pH} 8.5,9,9.2,9.4,9.6,9.8,10,10.2,10.4$, and 10.6. 182 CD spectra were acquired with solvent subtraction. To examine 183 the percentage of secondary structure of peptides, the spectra 184 were fitted using three different programs (CDSSTR, 185 
186 CONTINLL, and SELCON3) in CD Pro, ${ }^{18}$ and the averaged 187 percentage is reported. Alternatively, an in-house program was 188 used to fit the experimental spectra by finding optimal linear 189 combinations of published peptide spectra.

190 Sample Preparation for Mechanically Oriented Mem191 branes. A homogeneous mixture of POPE and POPG (3:1 192 molar ratio) and $\left[{ }^{15} \mathrm{~N}-\mathrm{L} 6,{ }^{2} \mathrm{H}_{3}\right.$-A8] GL13K was obtained by co193 dissolving the components in chloroform and methanol [1:1 194 (v:v)]. The solution was spread onto ultrathin cover glasses (8 $195 \mathrm{~mm} \times 22 \mathrm{~mm}$, Marienfeld, Lauda-Königshofen, Germany) and 196 dried, first in air and thereafter under high vacuum overnight. 197 Membranes were equilibrated at 93\% relative humidity, and in 198 cases in which it was necessary to obtain hydration in the 199 liquid-disordered state, the membranes were further exposed to 200 a higher temperature $(310 \mathrm{~K})$ before the glass slides were 201 stacked on top of each other and sealed in Teflon and then in a 202 plastic wrapping.

203 Sample Preparation for Magnetically Aligned Bicelles. $204\left[{ }^{15} \mathrm{~N}-\mathrm{L} 6,{ }^{2} \mathrm{H}_{3}-\mathrm{A} 8\right] \mathrm{GL} 13 \mathrm{~K}(2.5 \mathrm{mg})$ was added to a solution of $205131 \mathrm{mM}$ 1,2-dihexanoyl-sn-glycero-3-phosphocoline (DHPC). 206 This solution was added to the long chain lipids DMPC (1.2207 dimyristoyl-sn-glycero-3-phosphocoline) and DMPG [1,2-di208 myristoyl-sn-glycero-3-phospho-(1'-rac-glycerol)] in a 4:1 209 DMPC:DMPG molar ratio. The lipid composition was 210 arranged so that the DMPC:DMPG/DHPC sample has a 211 lipid concentration of $28 \%(\mathrm{w}: \mathrm{v})$ and a molar ratio $q$ 212 ([DMPC:DMPG] /[DHPC $]$ ) of 3.5 . To mimic physiological 213 conditions, a suitable volume of $100 \mathrm{mM} \mathrm{NaCl}$ in water at $\mathrm{pH}$ 2147.4 was added. Thus, the sample contained 78 wt \% water for 215 all preparations $(h=$ mass of water/total mass of phospholipids 216 and water). Hydrated samples were precipitated in a model 217 5804R Eppendorf benchtop centrifuge with a model F-45-3021811 rotor (Eppendorf AG, Hamburg, Germany) at $6500 \mathrm{rpm}$ $219(\sim 4500 \mathrm{~g})$ for $5 \mathrm{~min}$ and vigorously vortexed. The samples were 220 then frozen in liquid nitrogen for $30 \mathrm{~s}$, heated at $40{ }^{\circ} \mathrm{C}$ for 10 $221 \mathrm{~min}$ in a water bath, vigorously vortexed, and centrifuged again 222 at $6500 \mathrm{rpm}$ for $5 \mathrm{~min}$ at $4{ }^{\circ} \mathrm{C}$. This cycle was repeated three 223 times until a homogeneous suspension (viscous and trans224 lucent) was obtained at room temperature.

225 Solid-State NMR Spectroscopy. NMR experiments were 226 performed on Bruker Avance spectrometers operating either at $22711.7 \mathrm{~T}\left({ }^{1} \mathrm{H}\right.$ frequency of $\left.500 \mathrm{MHz}\right)$ or at $17.7 \mathrm{~T}(750 \mathrm{MHz})$. ${ }_{228}{ }^{31} \mathrm{P}$ NMR spectra were recorded at $202.4 \mathrm{MHz}(11.7 \mathrm{~T})$ 229 using a phase-cycled Hahn echo pulse sequence with gated 230 broadband proton decoupling. ${ }^{19}$ Typical acquisition parameters 231 were as follows: spectral window, $\pi / 2$ pulse width, and recycle 232 delay of $100 \mathrm{kHz}, 6 \mu \mathrm{s}$, and $5 \mathrm{~s}$, respectively, for mechanically 233 aligned samples and $20 \mathrm{kHz}, 7.1 \mu \mathrm{s}$, and $5 \mathrm{~s}$, respectively, for 234 aligned bicelles. Typically, 1024 scans were recorded. A line 235 broadening of $50 \mathrm{~Hz}$ was usually applied prior to Fourier 236 transformation. Quadrature detection was used in all cases. 237 Phosphorus chemical shifts were calibrated relative to $\mathrm{H}_{3} \mathrm{PO}_{4}$ 238 ( $85 \%$ in $\mathrm{H}_{2} \mathrm{O}, 0 \mathrm{ppm}$ ). Samples were allowed to equilibrate for 239 at least $20 \mathrm{~min}$ at $(40 \pm 1){ }^{\circ} \mathrm{C}$ before the NMR signal was 240 acquired.

${ }_{241}{ }^{2} \mathrm{H}$ NMR spectra were recorded at $76.8 \mathrm{MHz}$ by means of a 242 quadrupolar echo pulse sequence, ${ }^{20}$ with a $\pi / 2$ pulse width of $2437.5 \mu \mathrm{s}$ and a $50 \mu \mathrm{s}$ interpulse delay for mechanically oriented 244 samples (4.5 and $100 \mu \mathrm{s}$, respectively, for bicelles) and a recycle 245 delay of 1 s. Typically, 20000 scans were recorded, and a 246 Lorentzian noise filtering width of $200 \mathrm{~Hz}$ was applied prior to 247 Fourier transformation from the top of the echo signal. 248 Quadrature detection was used in all cases. The reference for solid-state deuterium powder patterns was set to zero and the 249 position of the carrier placed in the middle of the symmetric 250 Pake pattern (powder spectrum). Samples were allowed to 251 equilibrate for at least $20 \mathrm{~min}$ at $(40 \pm 1){ }^{\circ} \mathrm{C}$ before the NMR 252 signal was acquired. The $S_{\mathrm{CD}}$ order parameters in bilayer 253 membranes are proportional to the quadrupolar splittings: ${ }^{21,22} 254$ $S_{\mathrm{CD}}=4 \Delta \nu_{\mathrm{Q}} / 3 A_{\mathrm{Q}}$, where $A_{\mathrm{Q}}$ is $167 \mathrm{kHz}$.

Proton-decoupled ${ }^{15} \mathrm{~N}$ cross-polarization (CP) spectra were 256 acquired at $50.7 \mathrm{MHz}(11.7 \mathrm{~T})$ for mechanically aligned 257 samples and at $76.8 \mathrm{MHz}(17.7 \mathrm{~T})$ for bicelles. A CP pulse 258 sequence was used, with a spectral width, acquisition time, CP 259 contact time, $\pi / 2$ pulse width, and recycle delay of $50 \mathrm{kHz}, 10260$ $\mathrm{ms}, 0.8 \mathrm{~ms}, 10 \mu \mathrm{s}$, and $3 \mathrm{~s}$, respectively, for mechanically 261 oriented samples and $50 \mathrm{kHz}, 10 \mathrm{~ms}, 0.4 \mathrm{~ms}, 8 \mu \mathrm{s}$, and $2 \mathrm{~s}$ for 262 magnetically oriented bicelles; 67000 and 100000 scans were 263 recorded for mechanically oriented samples and bicelles, 264 respectively. The spectra were recorded at temperatures 265 above the gel to liquid phase transition. A $200 \mathrm{~Hz}$ exponential 266 line broadening was applied before Fourier transformation $\quad 267$

Spectral Simulations. All spectra were simulated using 268 Mathematica 3.0 (Wolfram Research, Champaign, IL). The 269 CSA tensors were expressed in spherical coordinates, and 270 spectra were calculated by integration of all possible 271 orientations using the assumed orientational distribution as a 272 weighting factor and folded with an inherent line broadening of 273 $300 \mathrm{~Hz}$ (in addition to the Gaussian mosaicity). For the ${ }^{15} \mathrm{~N} 274$ backbone, the CSA tensor $\sigma_{11}=62.5, \sigma_{22}=77.3$, and $\sigma_{33}=275$ 233.5 was taken into account, ${ }^{23}$ where $\sigma_{11}$ and $\sigma_{33}$ are in the 276 plane of the peptide bond defined by the $\mathrm{NH}$ vector and the 277 $\mathrm{C}_{\text {carboxyl }} \mathrm{N}$ vector. The angle between the $\mathrm{C}_{\text {carboxyl }} \mathrm{N}$ vector and 278 $\sigma_{33}$ is $105^{\circ}$. For ${ }^{31} \mathrm{P}$, an axial-symmetric tensor in which the 279 tensor elements were adjusted for the best fit was considered. 280 The line broadening was $1600 \mathrm{~Hz}$ to simulate the ${ }^{31} \mathrm{P}$ solid- 281 state NMR spectra and $2 \mathrm{kHz}$ for the ${ }^{2} \mathrm{H}$ solid-state NMR 282 spectra.

\section{RESULTS}

284

Solution NMR Studies in DPC Micelles. The high- 285 resolution structure of the GLK13 peptide was determined in 286 the presence of DPC micelles by multidimensional solution 287 NMR spectroscopy. A combination of $2 \mathrm{D}{ }^{1} \mathrm{H}-{ }^{1} \mathrm{H}$ TOCSY and 288 2D ${ }^{1} \mathrm{H}-{ }^{1} \mathrm{H}$ NOESY spectra was used to assign specific 289 resonances and to obtain NOE connectivities. Because of the 290 line broadening, due to the slow tumbling of peptide in 291 micelles, the $J$ coupling constants could not be extracted. ${ }^{24,25} 292$ Table S1 reports the resonance assignment with the exception 293 of alanine 8, which carried a deuterated side chain. Amino acid 294 spin systems were assigned following the sequence-specific 295 method (NOESY-walk) reported by Wüthrich, ${ }^{16}$ and a total of 296 151 NOEs (81 inter-residue and 70 intra-residue) were 297 identified. Several $d_{\mathrm{NN}}(i, i+1), d_{\alpha \mathrm{N}}(i, i+1)$, and $d_{\alpha \mathrm{N}}(i, i+298$ 2) were identified along the backbone of the peptide. Panels A 299 and $\mathrm{B}$ of Figure 1 show the backbone NOE pattern and the $300 \mathrm{fl}$ chemical shift index (CSI), respectively, for the peptide in DPC 301 micelles. The concomitant presence of both a deviation of more 302 than $-0.1 \mathrm{ppm}$ of the CSI value and the existence of $d_{\alpha \mathrm{N}}(i, i+303$ $3)$ and $d_{\alpha \mathrm{N}}(i, i+4)$ connectivities $^{26}$ is indicative of the presence 304 of $\alpha$-helical structures. The structures obtained from simulated 305 annealing calculations using XPLOR-NIH confirmed this first 306 analysis. Panels A and B of Figure 2 show the superposition of $307 \mathrm{f} 2$ the 20 lowest-energy conformers. The reported ensemble 308 shows an $\alpha$-helical structure between Lys-5 and Lys-11 (Figure 309 2C), and the superposition of backbone atoms in this region 310 
(A)

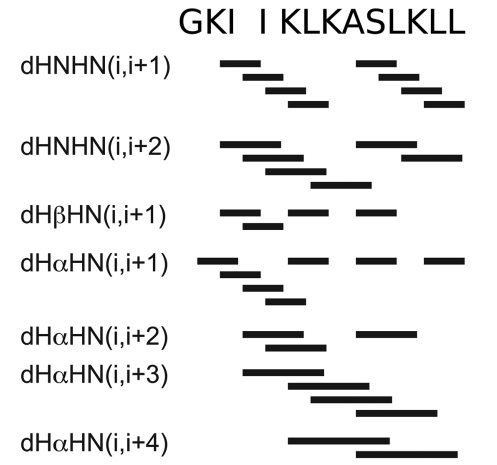

(B)

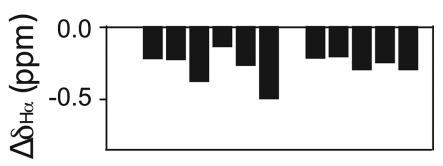

Figure 1. (A) Graphical summary of NOE constraints obtained from $1.9 \mathrm{mM} \mathrm{GL13K}$ in the presence of $189 \mathrm{mM} \mathrm{DPC}$ in $10 \mathrm{mM}$ phosphate buffer ( $\mathrm{pH} \mathrm{5}$ ) at $298 \mathrm{~K}$. (B) ${ }^{1} \mathrm{H}$ chemical shift index of $\mathrm{C}_{\alpha} \mathrm{H}$ for GL13K. Negative values are indicative of helical conformations. ${ }^{26}$

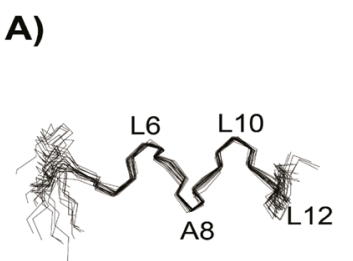

C)

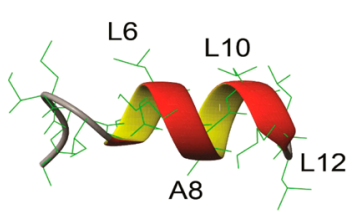

B)

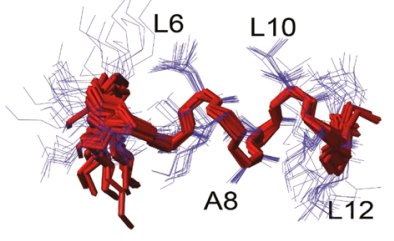

D)

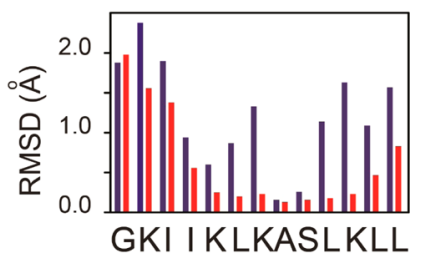

Figure 2. NMR structural ensemble of GL13K in DPC micellar environments using NOE restraints represented in Figure 1. Twenty lowest-energy conformers showing the convergence for the (A) backbone and (B) side chains. (C) Representative average structure of GL13K. (D) Residue-dependent root-mean-square deviations (RMSD) for the backbone (red) and side chains (blue) comparing the 20 lowest-energy conformers. The structures were fit onto the average conformation, and residues 5-11 were used for the superposition of the conformers.

311 gives a root-mean-square deviation (RMSD) of $0.29 \pm 0.13 \AA$ 312 for the backbone and a RMSD of $1.36 \pm 0.40 \AA$ for the heavy 313 atom side chains. In Figure 2D, the RMSD versus residue, blue 314 for side chains and red for the backbone, is reported.

315 CD Spectroscopic Titrations. The experimental con316 ditions used during the NMR structural analysis described 317 above are characterized by a high DPC:peptide molar ratio 318 with, on average, fewer than one peptide per micelle. The 319 helical structure thereby represents the peptides in their 320 isolated, monomeric state as they occur at a low level of 321 peptide association with, e.g., zwitterionic membranes. Indeed, 322 the helical secondary structure requires high detergent concentrations (Figure S1), and previous CD experiments 323 have indicated that the peptide only weakly interacts with 324 zwitterionic membranes. ${ }^{8}$ Furthermore, these experiments 325 showed that GL13K adopts $\beta$-sheet conformations upon 326 association with DOPG bilayers. To extend these previous 327 investigations, CD spectra were also recorded in the presence 328 of vesicles encompassing an intermediate amount of negatively 329 charged lipids, characteristic of bacterial membranes, namely, 330 3:1 POPE/POPG, as well as 3:1 (molar ratio) POPC/POPS 331 small unilamellar vesicles (Figure 3A,B). As in previous $332 \mathrm{f} 3$ investigations, considerable scattering hampers the evaluation 333 of spectra below $200 \mathrm{~nm}$ and deconvolution into different 334 secondary structures. ${ }^{8}$ However, the spectra closely resemble 335 those obtained in the presence of DOPG membranes where the 336 negative intensities at $217 \mathrm{~nm}$ were taken as an indicator of $\beta$ - 337 sheet conformation. ${ }^{8}$ Therefore, the transition from random 338 coil in solution to $\beta$-sheet-rich conformations already occurs 339 with liposomes containing moderate concentrations of 340 negatively charged lipids. Interestingly, the transition occurs 341 in a stepwise manner once the concentration of POPE and 342 POPG exceeds $600 \mu \mathrm{M}$ (Figure 3A).

343

The calculated net charge of GL13K is +5 at $\mathrm{pH} 7$ and 0 at 344 $\mathrm{pH} 14$ (pI). To further investigate the effect of peptide charge 345 on the structural preferences of GL13K, a $\mathrm{pH}$ titration was 346 performed by $\mathrm{CD}$ spectroscopy, using the $\mathrm{pH}$ range with the 347 highest change in net charge. A quantitative analysis of the 348 spectra at neutral $\mathrm{pH}$ is indicative of $10-15 \% \alpha$-helix, $25-30 \% 349$ $\beta$-sheet $/ \beta$-turn, and $55 \%$ unordered (Figure $3 \mathrm{~A}-\mathrm{C}$ ). When the 350 $\mathrm{pH}$ is increased to $10.6, \sim 20 \%$ of the random coil converts into 351 additional $\beta$-sheet contributions in a $\mathrm{pH}$-dependent manner 352 (Figure $3 \mathrm{C}$ ). The isosbestic point at $210 \mathrm{~nm}$ is indicative of a 353 two-state equilibrium. Notably, this transition was absent for 354 the randomized sequence GL13K-R1 [IGIKLLKSKLKAL- 355 $\mathrm{NH}_{2}$; cf. ref 6 (Figure 3D)]. In contrast, the latter peptide 356 shows a higher helix content at high $\mathrm{pH}$.

357

Solid-State NMR Studies of GL13K Associated with 358 POPE/POPG Bilayers. In a next step, the GL13K peptide 359 (labeled with ${ }^{15} \mathrm{~N}$ at leucine 6 and with methyl-deuterated 360 alanine at position 8) was reconstituted into oriented 361 phospholipid bilayers, with a phospholipid composition 362 mimicking that of bacterial membranes, and investigated by 363 solid-state NMR spectroscopy. ${ }^{27}$ The NMR parameters 364 observed in such samples are dependent on the molecular 365 alignment relative to the magnetic field direction of the NMR 366 spectrometer $\left(B_{\mathrm{o}}\right)$. When the sample normal is oriented parallel 367 to $B_{\mathrm{o}}$, the ${ }^{15} \mathrm{~N}$ chemical shift and ${ }^{2} \mathrm{H}$ quadrupolar splittings can 368 be analyzed in terms of peptide topology and orientational 369 distribution. $^{27}$ Furthermore, the effects of the peptide on the 370 orientational order, packing, and macroscopic phases can be 371 investigated using ${ }^{31} \mathrm{P}$ solid-state $\mathrm{NMR}^{28}$

Figure 4A shows the ${ }^{31} \mathrm{P}$ solid-state NMR spectrum of 3:1 $373 \mathrm{f4}$ (molar ratio) POPE/POPG bilayers in the presence of $2 \mathrm{~mol} \% 374$ GL13K supported by glass plates that are oriented with the 375 sample normal parallel to the magnetic field direction of the 376 spectrometer $\left(B_{\mathrm{o}}\right)$. The intensities around $30 \mathrm{ppm}$ are 377 indicative of phospholipids that are oriented with their long 378 axis parallel to $B_{0}{ }^{28}$ However, when compared to that of pure 379 lipid bilayers (cf. Figure 3 in ref 28), the line width of this 380 "oriented" signal intensity is quite broad (LWHH 19 ppm). 381 Furthermore, a major fraction of resonances extends over the 382 full chemical shift anisotropy, where intensities close to -15383 ppm are indicative of phopholipids in a perpendicular 384 orientation relative to the magnetic field direction (coinciding 385 


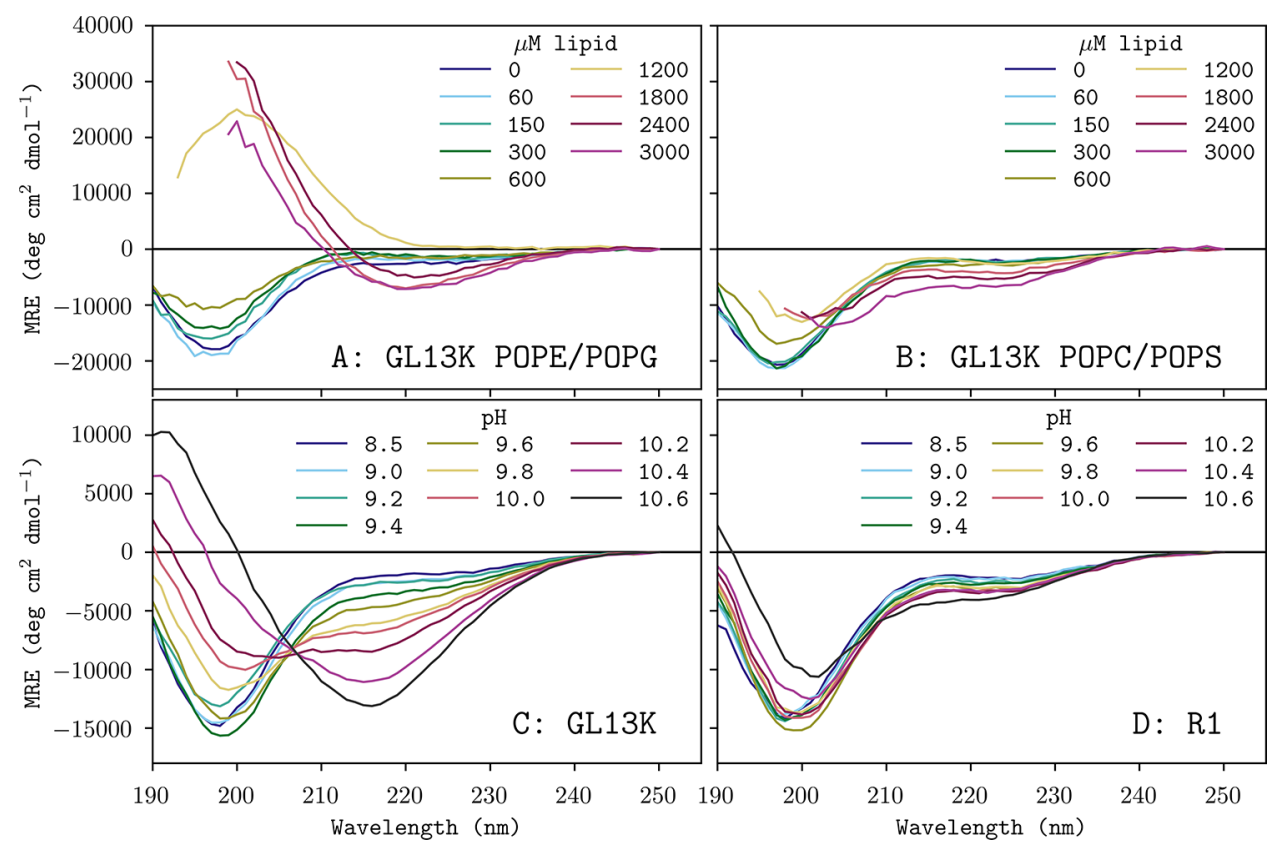

Figure 3. CD spectral titration of $60 \mu \mathrm{M}$ GL13K with (A) 0-3000 $\mu \mathrm{M}$ POPE/POPG (3:1 molar ratio) SUVs at $37{ }^{\circ} \mathrm{C}$ in $10 \mathrm{mM}$ Tris-HCl (pH 7.4$)$ and (B) POPC/POPS SUVs (3:1 molar ratio) at $25^{\circ} \mathrm{C}$ in $5 \mathrm{mM}$ Tris-HCl (pH 7.4). Spectra are corrected with control curves of SUVs only, but peptide-induced liposome aggregation causes some of the spectra to be severely affected by light scattering. Therefore, spectra at the highest lipid concentrations were truncated below $200 \mathrm{~nm}$. CD spectra of (C) GL13K and (D) GL13K-R1 in buffers from pH 8.5 to 10.6. GL13K but not GK13K-R1 gradually shifts from random coil to more $\beta$-turn secondary structure with an increase in pH. GL13K-R1 but not GL13K exhibits more $\alpha$-helix at high $\mathrm{pH}$.

386 with the sample normal). Among other possibilities, the 387 combination of $36 \%$ lipids oriented with their long axis parallel 388 to the sample normal (18.8 ppm LWHH) and 64\% randomly 389 oriented (powder pattern) results in a related line shape. 390 Regardless of the detailed supramolecular assembly, the spectra 391 are indicative that the peptide has a high capacity to disrupt the 392 membrane orientational order. In comparison, the disruption of 393 orientational order at comparable P:L ratio is much higher for 394 GL13K than for other cationic amphipathic antimicrobial 395 peptides such as the helical magainins, ${ }^{28-30}$ phyloseptins, ${ }^{31}$ or 396 the $\beta$-sheet arenicin. ${ }^{32}$ On the other hand, dermadistinctin $\mathrm{K}^{9}$ 397 and protegrin ${ }^{33}$ also show pronounced disordering effects upon 398 being investigated in the context of supported lipid bilayers.

399 The ${ }^{15} \mathrm{~N}$ and ${ }^{2} \mathrm{H}$ solid-state NMR spectra of the labeled 400 peptide within the same sample were also investigated (Figure $4014 \mathrm{~B}, \mathrm{C})$. To a first approximation, the ${ }^{15} \mathrm{~N}$ spectrum represents 402 the alignment of ${ }^{15} \mathrm{~N}-\mathrm{H}$ vectors relative to the magnetic field 403 direction and, thus, the main axis of helical peptides relative to 404 the sample normal. ${ }^{34}$ Whereas values of $\sim 200 \mathrm{ppm}$ are 405 associated with transmembrane helical peptides (or $\mathrm{NH}$ vectors 406 parallel to the sample normal), chemical shifts of $<100 \mathrm{pm}$ are 407 indicative of perpendicular orientations. ${ }^{34}$ When samples are 408 reconstituted into mechanically supported phopholipid bilayers 409 where the sample normal is oriented parallel to the magnetic 410 field direction, most ${ }^{15} \mathrm{~N}$ intensities appear at $85 \mathrm{ppm}$ with a $411 \mathrm{LWHH}$ of $\sim 47 \mathrm{ppm}$, indicating that the $\mathrm{N}-\mathrm{H}$ vectors are 412 oriented predominantly perpendicular to $B_{\mathrm{o}}$ (Figure $4 \mathrm{~B}$ ). An 413 angle between $\mathrm{NH}$ and $B_{\mathrm{o}}$ of $\sim 100^{\circ}$ represents well the spectral 414 maximum.

415 Finally, the ${ }^{2} \mathrm{H}$ quadrupolar splitting of the ${ }^{2} \mathrm{H}_{3} \mathrm{C}$ alanine 416 methyl groups is a function of the $\mathrm{C}_{\alpha}-\mathrm{C}_{\beta}$ angle relative to the 417 magnetic field direction/sample normal and can be very 418 sensitive to even small changes in membrane alignment. ${ }^{35}$ 419 Similar to the ${ }^{31} \mathrm{P}$ solid-state NMR spectra, the ${ }^{15} \mathrm{~N}$ and ${ }^{2} \mathrm{H}$ spectra exhibit broad spectral line shapes that could arise from a 420 combination of powder pattern line shapes, where the elevated 421 shoulders at $\pm 35 \mathrm{kHz}$ could arise from a circular orientational 422 distribution or represent a composite of oriented contributions 423 and powder pattern line shapes (Figure 4C). The latter 424 contributions are expected to arise, e.g., from a twisted $\beta$-sheet. 425

The GL13K peptide was also investigated in the presence of 426 phospholipid bicelles, which, at a lipid concentration of $28 \% 427$ $(\mathrm{w}: \mathrm{v})$, a molar ratio $q$ ([DMPC:DMPG $] /[\mathrm{DCPC}])$ of 3.5 , and 428 a temperature of $310 \mathrm{~K}$, have been shown to align in the 429 magnetic fields of NMR spectrometers. ${ }^{36,37}$ Interactions of the 430 peptide with the anionic bilayer ensure that the cationic GL13K 431 also aligns in the magnetic field. In contrast to that of the 432 mechanically oriented sample, the bilayer normal of the bicelle 433 is oriented perpendicular to $B_{\mathrm{o}}$.

Because of the fast rotation of the phospholipids around their 435 long axis, the ${ }^{31} \mathrm{P}$ NMR spectra are characterized by two 436 components, namely, the averaged tensor elements $\sigma_{\|}$and $\sigma_{\perp}, 437$ representing the components parallel and perpendicular to the 438 rotation axis, respectively. ${ }^{38,39}$ Whereas in the mechanically 439 oriented sample, the interaction of the ${ }^{31} \mathrm{P}$ chemical shift is 440 represented by $\sigma_{\|}$, tilting the membrane by $90^{\circ}$ aligns $\sigma_{\perp} 441$ parallel to $B_{\mathrm{o}}$ and thereby represents the observed chemical 442 shift. Therefore, in Figure 4D, the signal intensities at -14 and 443 $-11 \mathrm{ppm}$ are indicative of oriented PC and PG components, 444 respectively, whereas the intensity at $\sim 0 \mathrm{ppm}$ has been 445 associated with the short chain DHPC lipids that freely change 446 orientation by diffusing fast within the bicellar rim struc- 447 ture. $^{40,41}$

The ${ }^{15} \mathrm{~N}$ spectrum exhibits a broad distribution of resonances 449 ranging from 224 to $65 \mathrm{ppm}$, indicative of $\mathrm{NH}$ vector 450 orientations ranging from parallel to perpendicular relative to 451 $B_{\mathrm{o}}$. Rotation around the bilayer normal, which in the bicellar 452 case is oriented perpendicular to $B_{0}$, results in many different 453 

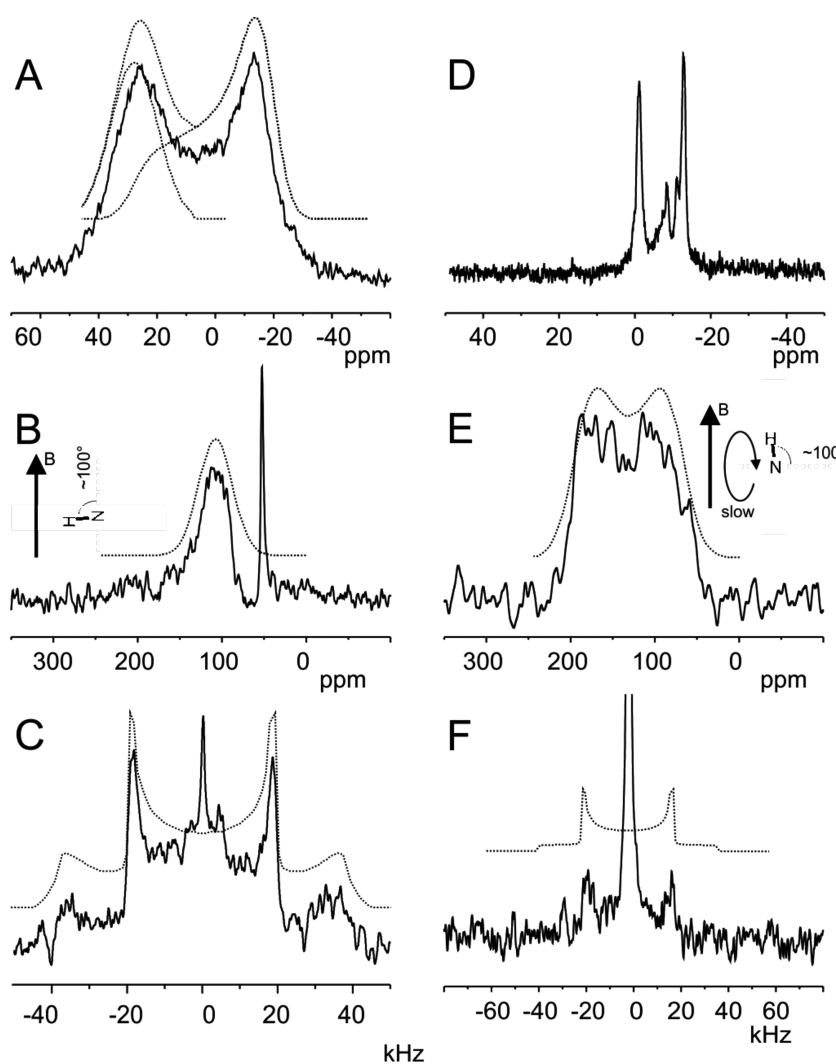

G

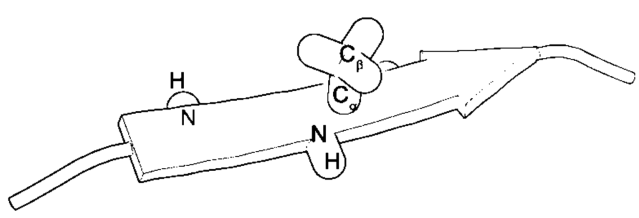

Figure 4. Solid-state NMR spectra of $\left[{ }^{15} \mathrm{~N}-\mathrm{Leu} 6,{ }^{2} \mathrm{H}_{3}\right.$-Ala8 $] \mathrm{GL} 13 \mathrm{~K}$ reconstituted into (A-C) mechanically oriented POPE/POPG (3:1) bilayers and $(\mathrm{D}-\mathrm{F})[\mathrm{DMPC}: \mathrm{DMPG}] /[\mathrm{DCPC}]$ magnetically aligned bicelles at $310 \mathrm{~K}$. The first row (A and $\mathrm{D})$ shows the corresponding ${ }^{1} \mathrm{H}$-decoupled ${ }^{31} \mathrm{P}$ solid-state NMR spectra of the sample phospholipids, the second row (B and $\mathrm{E}$ ) the ${ }^{15} \mathrm{~N}$ NMR spectra, and the third row ( $\mathrm{C}$ and $\mathrm{F}$ ) the ${ }^{2} \mathrm{H}$ NMR spectra obtained from the reconstituted $\left[{ }^{15} \mathrm{~N}\right.$-Leu6, ${ }^{2} \mathrm{H}_{3}$-Ala8 $]$ GL13K peptide. The ${ }^{31} \mathrm{P}$ solid-state NMR and the mechanically oriented samples were investigated at $11.8 \mathrm{~T}$, and the ${ }^{15} \mathrm{~N}$ and ${ }^{2} \mathrm{H}$ spectra of the peptide in bicelles were recorded at $17.7 \mathrm{~T}(\mathrm{E}$ and F). The dotted traces correspond to simulated spectra: (A) $36 \%$ oriented with $18.8 \mathrm{ppm} \mathrm{LWHH}$ and 64\% powder with $11.8 \mathrm{ppm}$ $\mathrm{LWHH}$ and (B) oriented with an angle between the $\mathrm{NH}$ bond and the membrane normal of $100^{\circ}$ (membrane normal parallel to the magnetic field) and $47 \mathrm{ppm}$ LWHH. (C) Powder pattern line shape $(2 / 3)$ combined with a spectrum that results from a mean alignment of the $\mathrm{C} \alpha-\mathrm{C} \beta$ bond parallel to the membrane normal with $45^{\circ}$ mosaicity ( $1 /$ $3)$. (E) Integral of all possible orientations with an angle between $\mathrm{NH}$ and the membrane normal of $100^{\circ}$ (membrane normal perpendicular to the magnetic field) and $47 \mathrm{ppm}$ LWHH. (F) Powder pattern line shape. The membrane alignment is sketched as a gray bar next to panels $B$ and $E$ together with the approximate alignment of the $\mathrm{N}-\mathrm{H}$ bond. A sheet with the relative orientations of the $\mathrm{NH}$ bond and the $\mathrm{C} \alpha-\mathrm{C} \beta$ vector of the alanine side chain is shown in panel $\mathrm{G}$.

454 peptide orientations relative to $B_{0}$. Indeed, taking into account 455 the $100^{\circ} \mathrm{NH}$ alignment relative to the sample normal, which 456 has been found to represent well the ${ }^{15} \mathrm{~N}$ spectrum of the 457 mechanically oriented samples (Figure 4B), also explains well 458 the bicellar ${ }^{15} \mathrm{~N}$ spectrum (Figure $4 \mathrm{E}$ ) under the condition at 459 which motional averaging around the bilayer normal is slow on the $10^{4} \mathrm{~Hz}$ time scale of the ${ }^{15} \mathrm{~N}$ chemical shift anisotropy. ${ }^{42}{ }_{460}$ Finally, the ${ }^{2} \mathrm{H}$ solid-state spectrum of GL13K associated with 461 the bicellar system is shown in Figure 4F. The signal:noise ratio 462 remains modest despite 3 days of signal averaging, and 463 therefore, the spectrum cannot be analyzed in detail. For 464 comparison, a powder pattern line shape, making a major 465 contribution also to Figure 4C, is shown on top of the 466 spectrum, showing that the maximal peak intensities can be 467 associated with such a (close to) random distribution of $\mathrm{C}_{\alpha}-\mathrm{C}_{\beta} 468$ vectors.

Finally, we used ${ }^{2} \mathrm{H}$ solid-state NMR spectroscopy to 470 investigate the effect of GL13K on the fatty acyl chain packing 471 of the bilayers. Mixed POPE/POPG membranes in which all 472 ${ }^{1} \mathrm{H}$ positions of the palmitoyl chain of either POPE or POPG in 473 the bacterial mimetic membrane were exchanged with 474 deuterium were studied. The resulting ${ }^{2} \mathrm{H}$ solid-state NMR 475 spectra encompass signals from the different $\mathrm{CD}_{2}$ segments and 476 one $\mathrm{CD}_{3}$ segment, each contributing a powder pattern line 477 shape, where the distance between the two main peaks defines 478 the quadrupolar splitting. ${ }^{21,43}$ Without motions, the static 479 splitting would amount to $125 \mathrm{kHz}$. However, in the liquid 480 crystalline bilayers investigated here, motions and cis-trans 481 isomerizations result in a considerable reduction, which is 482 evident in the ${ }^{2} \mathrm{H}$ solid-state NMR spectra shown in panels A 483 and $\mathrm{C}$ of Figure 5. Notably, the segments exhibit more $484 \mathrm{fs}$ motional freedom in the hydrophobic interior than the region 485 of the carbonyls does. The order parameter profiles were 486 extracted separately for both types of phospholipid (Figure 487 $5 \mathrm{~B}, \mathrm{D})$. In the presence of $2 \mathrm{~mol} \%$ GL13K, a considerable 488 decrease in the level of packing order is observed for both 489 lipids. The decrease is $\sim 20 \%$ for the POPE and 10\% for POPG 490 palmitoyl chains.

\section{DISCUSSION}

492

GL13K is a short cationic, amphipathic peptide that efficiently 493 interacts with membranes. We have previously found that 494 GL13K is effective against the Gram-negative bacterium 495 Escherichia coli [minimum inhibitory concentration (MIC) of 496 $5 \mu \mathrm{g} / \mathrm{mL}$ ] and Pseudomonas aeruginosa (MIC of $8 \mu \mathrm{g} / \mathrm{mL}$ ), ${ }^{6} 497$ whereas the peptide is not effective against the oral Gram- 498 negative pathogen Porphyromonas gingivalis. ${ }^{6}$ Similarly, activity 499 is limited against Gram-positive bacteria, including Streptococcus 500 gordonii (MIC of $64 \mu \mathrm{g} / \mathrm{mL}$ ) (H. Hirt and S.-U. Gorr, 501 unpublished observations), Staphyloccocus aureus (MIC of 41502 $\mu \mathrm{g} / \mathrm{mL}$ ) (S.-U. Gorr, unpublished observations), and Enter- 503 occocus faecalis (MIC of $>512 \mu \mathrm{g} / \mathrm{mL}$ ) (H. Hirt and S.-U. Gorr, 504 unpublished observations). However, the peptide kills up to 505 99.99\% of the bacteria in existing biofilms of $P$. aeruginosa. ${ }^{7} \quad 506$

Here we demonstrate that GL13K exhibits random coil 507 conformations in aqueous solution, helical structures in DPC 508 micelles, and $\beta$-sheet-rich conformations in the presence of 509 liposomes composed of $25 \%$ negatively charged lipids, which 510 were also observed previously upon association with DOPG 511 liposomes. ${ }^{8}$ In the presence of phosphatidylcholine liposomes, 512 the extent of membrane association of this highly charged 513 peptide is low and the CD spectra represent mostly the peptide 514 that remains in solution. Because light scattering interferes with 515 optical spectroscopies, in particular when extending into the 516 ultraviolet spectral region, only dilute liposomal suspensions 517 have been investigated by CD spectroscopy. In contrast, during 518 the NMR structure analysis, presented here, high DPC 519 concentrations were used, which brings the binding equilibrium 520 to the membrane-associated state. Therefore, the NMR 521 

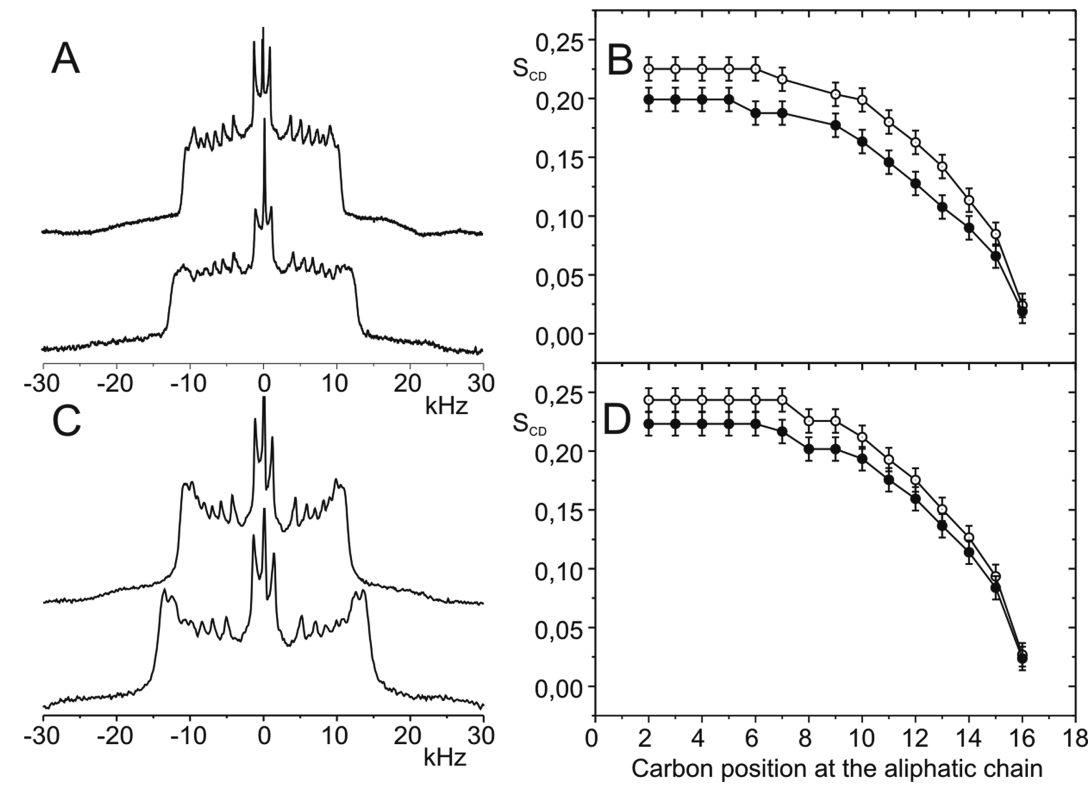

Figure 5. ${ }^{2} \mathrm{H}$ NMR spectra of $\left[{ }^{15} \mathrm{~N}-L e u 6,{ }^{2} \mathrm{H}_{3}\right.$-Ala8 $]$ GL13K embedded in (A) POPE $/\left[{ }^{2} \mathrm{H}_{31}\right] \mathrm{POPE} / \mathrm{POPG}$ and (C) POPE/POPG/ $\left[{ }^{2} \mathrm{H}_{31}\right] \mathrm{POPG}$ vesicles at $310 \mathrm{~K}$ in $10 \mathrm{mM}$ Tris-HCl buffer. In each panel, the spectra in the presence of $2 \mathrm{~mol} \% \mathrm{GL} 13 \mathrm{~K}$ are shown above the spectra obtained from pure lipid bilayers. (B and D) Corresponding order parameters as a function of the carbon position on the aliphatic chain in the presence $(\mathbf{)})$ and absence $(O)$ of GL13K.

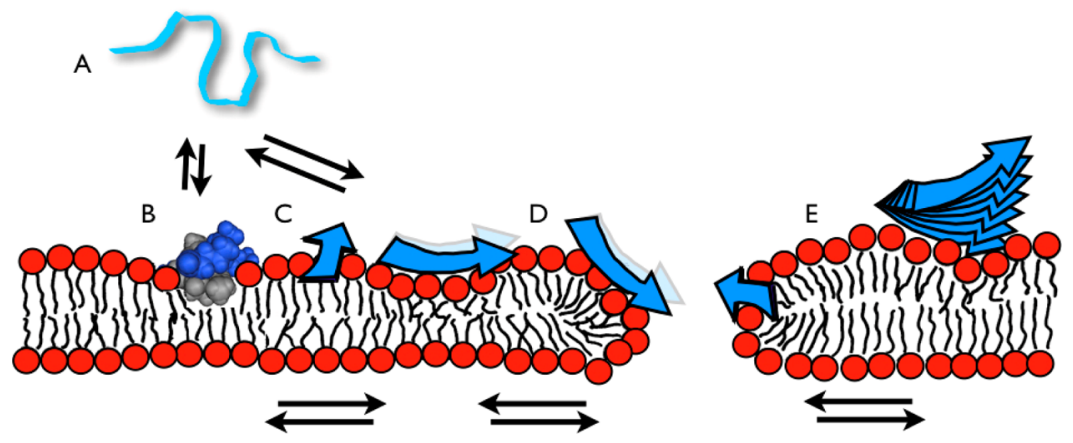

Figure 6. Model of the equilibria governing the random coil (A), the helical monomeric form (B), $\beta$-strands (C and D), and $\beta$-sheet aggregates of GL13K (E). A membrane opening and a side-on aligned $\beta$-sheet with its $\mathrm{N}-\mathrm{H}$ vectors oriented parallel to the sample normal are shown in part $\mathrm{D}$. Notably, parts B-E can result in membrane deformations and ultimately bilayer openings.

522 structural data, in combination with previously published 523 investigations, ${ }^{8}$ indicate that depending on the membrane 524 composition and other environmental parameters, GL13K 525 adopts helical or $\beta$-sheet-rich secondary structures in the 526 presence of membranes.

527 The helical structure determined in the presence of DPC 528 micelles (detergent:peptide molar ratio of 100) extends from 529 residue 5 to 11 . The resulting three-dimensional fold results in 530 a small hydrophobic surface of leucines 6 and 10, opposed by 531 lysines 5, 7, and 11, which suggest an interfacial association 532 (Figure 6). As with other cationic amphipathic peptides, the 533 resulting hydrophobic interactions alone are weak, ${ }^{44}$ but 534 membrane association is enhanced by electrostatic attrac535 tion. $^{8,45}$ Notably, in the DPC micellar system, where one 536 micelle consists of $\sim 40$ detergent molecules, ${ }^{46}$ there is on 537 average fewer than one peptide per micelle, which probably also 538 represents the situation in which the peptide associates with 539 neutral membranes and the resulting low peptide:lipid ratios. 540 Because of its weak interactions with zwitterionic membranes, 541 the NMR structure presented here is thereby the only biophysical data of the peptide describing the membrane- 542 associated state at low concentrations.

In the presence of DOPG membranes, CD spectroscopy has 544 revealed a predominantly $\beta$-sheet conformation. ${ }^{8}$ Clearly, the 545 high negative charge density of this lipid bilayer increases the 546 local peptide concentration along the membrane surface and 547 thereby the apparent binding constant. Here we extended these 548 investigations to intermediate concentrations of negatively 549 charged lipids by adding $75 \% \mathrm{PE}$, a lipid preponderant in 550 bacterial membranes. Also, under these conditions, CD spectra 551 are indicative of a $\beta$-sheet conformation of GL13K (Figure 552 $3 \mathrm{~A}, \mathrm{~B})$. The combination of ${ }^{15} \mathrm{~N}$ and ${ }^{2} \mathrm{H}$ solid-state NMR data 553 suggests a predominant alignment of the sheet along the 554 membrane surface as depicted in Figure 4G, with considerable 555 twist, and slow rotational diffusion around the membrane 556 normal probably due to peptide association (Figure 4E), when 557 at the same time the orientational order at the level of the 558 phospholipid headgroup is severely disturbed (Figure 4A). $\quad 559$

It is tempting to speculate that the resulting high peptide 560 density within the membrane favors peptide-peptide inter- 561 actions concomitant with $\beta$-sheet formation. The data do not 562 
563 reveal the oligomerization state of GL13K in the membrane. 564 However, it should be mentioned that the appearance of ${ }^{15} \mathrm{~N}$ 565 and ${ }^{2} \mathrm{H}$ spectra varies with the solvent used during the sample 566 preparation, suggesting that the equilibria between mono- and 567 oligomeric states are affected. On a related note, increasing the $568 \mathrm{pH}$ in the absence of membranes results in the formation of $\beta$ 569 sheet structures (Figure 3C), whereas the randomized GL13$570 \mathrm{R} 1$ sequence exhibits additional $\alpha$-helical features (Figure 3D). 571 Such data indicate that a propensity for $\beta$-sheet is inherent in 572 the detailed amino acid arrangement of GL13K, whereas the 573 amino acid composition per se is in agreement with helical 574 secondary structures.

575 In analogy with previous investigations, ${ }^{32,47}$ the ensemble of 576 data suggests that the GL13K-membrane interactions are 577 governed by a number of equilibria encompassing random coil, $578 \alpha$-helical, and $\beta$-turn conformations as well as $\beta$-sheet 579 aggregates (Figure 6). Catestatin has similarly been found to 580 encompass a seven-residue $\alpha$-helical conformation in micellar 581 solutions with the remainder of the 21-residue peptide 582 unstructured. ${ }^{48}$ In contrast, the shortened cateslytin analogue 583 exhibits CD spectra characteristic of $\beta$-turn sheet conformations 584 in the presence of negatively charged liposomes. ${ }^{49}$ Notably, the 585 carboxy-terminal residue of cateslytin coincides with the helical 586 boundary of catestatin, suggesting that the missing residues 587 stabilize the helical domain of catestatin. As a result of the 588 missing intramolecular H-bonds typical for helical structures, an 589 intermolecular H-bonding network forms in the case of 590 cateslytin. The cateslytin sequence and the GL13K peptides 591 share a similar size (15 and 13 amino acid residues, 592 respectively), a high density of positive charges $(5+)$, and an $593 \alpha$-helix $-\beta$-sheet transition/equilibrium in membrane environ594 ments (Figure 6). The fusion peptide of HIV has also been 595 found to exhibit an equilibrium between $\alpha$-helical and $\beta$-turn 596 secondary structures that is dependent on the lipid 597 composition. $^{50}$

598 In its helical conformation, the peptide probably interacts 599 with the membrane interface through hydrophobic (three or 600 four leucines) and electrostatic interactions (four lysines and 601 the amino terminus), which results in a wide range of 602 topologies (Figure 4B,C). At the same time, the formation of 603 aggregates is favored by high peptide densities at the membrane 604 and the screening of excess positive charges on the peptide by 605 anionic PG headgroups. Thereby, the high surface concen606 tration in the presence of POPG competes efficiently with 607 helical membrane partitioning and results in the formation of $\beta$ 608 sheets. On a related note, the $\beta$-sheet secondary structures 609 observed at high $\mathrm{pH}$ are probably a result of weakened 610 repulsive electrostatic contributions (Figure 3C).

611 Importantly, many cationic linear AMPs have been suggested 612 to kill bacteria by forming openings in the cytoplasmic 613 membranes that lead to the collapse of the electrochemical 614 gradient and the release of intracellular contents. They do so by 615 inserting their amphipathic structures into the membrane 616 surface rather than by fully spanning the lipid bilayers. ${ }^{45,51}$ 617 Potential mechanisms that have been proposed to explain the 618 molecular structure of such membrane openings include, first, 619 the formation of a barrel stave arrangement (cf. refs 32 and 47). 620 Second, the 15-residue cationic peptide cateslytin has been 621 suggested to form $\beta$-sheets oriented along the membrane 622 surface. At peptide:lipid ratios of $1: 15$, these were shown to 623 selectively interact with anionic lipids, to cause an increased 624 level of order of the fatty acyl chains of negatively charged lipids 625 and lateral phase separation of 1:1 DMPC/DMPS mem- branes. $^{49}$ The packing defects along the resulting phase 626 boundaries are thought to be susceptible to membrane passage. 627 Notably, here we found a strong membrane disordering effect, 628 which is stronger on the zwitterionic PE than on the PG 629 component of the mixed membranes (Figure 5).

630

Third, the partitioning of amphipathic peptides into the 631 membrane interface has previously been shown to cause 632 considerable curvature strain and to disrupt membrane 633 packing. ${ }^{45}$ In the case of GL13K, this effect is quite pronounced 634 both when the global order of the oriented membranes is 635 monitored by ${ }^{31} \mathrm{P}$ solid-state NMR spectroscopy (Figure 3A) 636 and when the fatty acyl chain order is investigated (Figure 5). It 637 is thought that this can be due to molecules that partition in the 638 membrane interface, which thereby increase membrane 639 curvature strain (Figure 6). Interestingly, the membrane 640 disordering effect is more pronounced for POPE than for 641 POPG in mixed membranes, which is surprising considering 642 that other cationic peptides have been shown to preferentially 643 associate with the negatively charged lipid in PC/PS/ 644 cholesterol membranes. ${ }^{52}$

Our results do not directly address the activity of GL13K in 646 the more complex environment of bacterial biofilms that are 647 organized in an extracellular matrix. However, the peptide- 648 peptide interactions concomitant with $\beta$-sheet formation and 649 the resulting membrane disruption may also affect bacterial 650 interactions and disrupt their organization in biofilms. Indeed, 651 when biofilms of $P$. aeruginosa are treated with GL13K, the 652 bacteria are killed in place and the biofilm appears to be 653 destabilized and is dispersed or shed from the surface, as 654 evidenced by scanning electron microscopy. ${ }^{7} \quad 655$

Selectivity for bacterial versus healthy eukaryotic cells arises 656 from the high negative surface charge and the high trans- 657 membrane electrical potential that lead to an increased 658 concentration of the peptides along the prokaryotic surface. ${ }^{53,54} 659$ Therefore, the $\alpha$-helical structure at the low peptide:lipid ratios 660 that occur in the presence of zwitterionic membranes versus the 661 $\beta$-sheet conformations observed upon exposure to anionic 662 lipids also reflects the selectivity of GL13K for bacterial cells 663 and its lack of toxicity against eukaryotic cells. Furthermore, 664 cholesterol protects the membranes of eukaryotic organisms. In 665 general, the mode of interaction depends on peptide structure 666 (distribution of hydrophilic and hydrophobic amino acids), 667 peptide concentration, and the physicochemical properties of 668 the membrane (concept reviewed in ref 45), suggesting that a 669 delicate balance of interactions needs to be considered. 670

In conclusion, whereas the highly charged GL13K peptide is 671 strongly attracted to negatively charged membranes, hydro- 672 phobic association is rather weak. At low peptide:detergent/ 673 lipid ratios, the peptide adopts a helical conformation upon 674 interacting with membranes, which converts to $\beta$-sheet-rich 675 supramolecular arrangements with highly membrane disruptive 676 properties. The high charge and small hydrophobic phase of 677 this short peptide antibiotic thereby result in high conforma- 678 tional plasticity.

679

\section{ASSOCIATED CONTENT}

680

S Supporting Information

681

The Supporting Information is available free of charge on the 682 ACS Publications website at DOI: 10.1021/acs.bio- 683 chem.7b00526. 
NMR resonance assignments, statistics for the structure calculations, and a CD spectroscopic titration of DPC into a GL13K solution (PDF)

\section{AUTHOR INFORMATION}

\section{Corresponding Author}

690 *Address: 4, rue Blaise Pascal, 67070 Strasbourg, France. 691 Telephone: +33 3688513 03. Fax: +33 3688517 35. E-mail: 692 bechinge@unistra.fr.

\section{ORCID 요}

694 Sarah E. D. Nelson: 0000-0001-6210-5009

695 Louic Vermeer: 0000-0003-1815-7412

696 Conrado Aparicio: 0000-0003-2969-6067

697 Burkhard Bechinger: 0000-0001-5719-6073

\section{Author Contributions}

699 N. Harmouche and C. Aisenbrey contributed equally to this 700 work.

\section{Funding}

702 This research was supported by Grant 1R01DE017989 from 703 the National Institute for Dental and Craniofacial Research (S.704 U.G.), Grant GM 64742 from the National Institute for 705 General Medical Sciences (G.V.), and a fellowship supported 706 by Grant R90DE023058 from the National Institute of Dental 707 and Craniofacial Research (X.C.). Research funds were 708 provided by the University of Minnesota School of Dentistry 709 (S.-U.G.) and The Office of the Vice-president for Research at 710 the University of Minnesota, Project 55466 of the Grant-in-Aid 711 of Research, Artistry and Scholarship Program (C. Aparicio). 712 B.B. was supported by a sabbatical stay at the University of 713 Minnesota School of Dentistry that was generously supported 714 by the School's Lasby Visiting Professor Fellowship and the 715 University of Strasbourg. B.B. received additional support from 716 the Agence Nationale de la Recherche (Projects TRANSPEP 717 07-PCV-0018, membraneDNP 12-BSV5-0012, and MemPep718 Syn 14-CE34-0001-01 and the LabEx Chemistry of Complex 719 Systems 10-LABX-0026_CSC), the RTRA International 720 Center of Frontier Research in Chemistry, the French 721 Foundation for Medical Research (FRM), the University of 722 Strasbourg, the CNRS, and the Région Alsace.

723 Notes

724 The authors declare no competing financial interest.

\section{ACKNOWLEDGMENTS}

726 We are grateful to Delphine Hatey for the preparation of 727 peptides.

\section{$728 \square$ ABBREVIATIONS}

$729 \mathrm{CD}$, circular dichroism; DHPC, 1,2-dihexanoyl-sn-glycero-3730 phosphocholine; DMPC, 1,2-dimyristoyl-sn-glycero-3-phospho731 choline; DMPG, 1,2-dimyristoyl-sn-glycero-3-(1'-rac-glycerol) 732 sodium salt; DOPC, 1,2-dioleoyl-sn-glycero-3-phosphocholine; 733 DOPG, 1,2-dioleoyl-sn-glycero-3-(1'-rac-glycerol) sodium salt; 734 DPC, dodecylphosphocholine; HPLC, high-performance liquid 735 chromatorgraphy; LWHH, line width at half-height; MAS, 736 magic angle spinning; NMR, nuclear magnetic resonance; 737 NOE, nuclear Overhauser effect; NOESY, nuclear Overhauser 738 effect spectroscopy; MALDI, matrix-assisted laser desorption 739 ionization; POPC, 1-palmitoyl-2-oleoyl-sn-glycero-3-phospho740 choline; POPE, 1-palmitoyl-2-oleoyl-sn-glycero-3-phosphoetha741 nolamine; POPG, 1-palmitoyl-2-oleoyl-sn-glycero-3-(1'-rac742 glycerol) sodium salt; POPS, 1-palmitoyl-2-oleoyl-sn-glycero- 3-phosphoserine; rh, relative humidity; SDS, sodium dodecyl 743 sulphate; TFA, trifluoroacetic acid; TOCSY, total correlation 744 spectroscopy.

\section{REFERENCES}

(1) Fan, L., Sun, J., Zhou, M., Zhou, J., Lao, X., Zheng, H., and Xu, H. 747 (2016) DRAMP: a comprehensive data repository of antimicrobial 748 peptides. Sci. Rep. 6, 24482.

(2) Bechinger, B., and Gorr, S. U. (2017) Antimicrobial Peptides: 750 Mechanisms of Action and Resistance. J. Dent. Res. 96, 254-260. 751

(3) Mikut, R., Ruden, S., Reischl, M., Breitling, F., Volkmer, R., and 752 Hilpert, K. (2016) Improving short antimicrobial peptides despite 753 elusive rules for activity. Biochim. Biophys. Acta, Biomembr. 1858, 754 1024-1033.

(4) Beamer, L. (2003) Structure of human BPI (bactericidal/ 756 permeability-increasing protein) and implications for related proteins. 757 Biochem. Soc. Trans. 31, 791-794.

(5) Dankesreiter, S., Hoess, A., Schneider-Mergener, J., Wagner, H., 759 and Miethke, T. (2000) Synthetic endotoxin-binding peptides block 760 endotoxin-triggered TNF-\{alpha\} production by macrophages in vitro 761 and in vivo and prevent endotoxin-mediated toxic shock. J. Immunol. 762 164, 4804-4811.

(6) Abdolhosseini, M., Nandula, S. R., Song, J., Hirt, H., and Gorr, S. 764 U. (2012) Lysine substitutions convert a bacterial-agglutinating 765 peptide into a bactericidal peptide that retains anti-lipopolysaccharide 766 activity and low hemolytic activity. Peptides 35, 231-238. 767

(7) Hirt, H., and Gorr, S. U. (2013) Antimicrobial peptide GL13K is 768 effective in reducing biofilms of Pseudomonas aeruginosa. Antimicrob. 769 Agents Chemother. 57, 4903-4910.

(8) Balhara, V., Schmidt, R., Gorr, S. U., and Dewolf, C. (2013) 771 Membrane selectivity and biophysical studies of the antimicrobial 772 peptide GL13K. Biochim. Biophys. Acta, Biomembr. 1828, 2193-2203. 773

(9) Verly, R. M., de Moraes, C. M., Resende, J. M., Aisenbrey, C., 774 Bemquerer, M. P., Pilo-Veloso, D., Valente, A. P., Almeida, F. C., and 775 Bechinger, B. (2009) Structure and membrane interactions of the 776 antibiotic peptide dermadistinctin $\mathrm{k}$ by solution and oriented $15 \mathrm{~N}$ and 777 31 P solid-state NMR spectroscopy. Biophys. J. 96, 2194-2203. 778

(10) Bax, A. D., and Davis, D. G. (1985) MLEV-17-based two- 779 dimensional homonuclear magnetization transfer spectroscopy. J. 780 Magn. Reson. 65, 355-360.

(11) Kumar, A., Ernst, R. R., and Wüthrich, K. (1980) A two- 782 dimensional nuclear Overhauser enhancement (2D NOE) experiment 783 for the elucidation of complete proton-proton cross-relaxation 784 networks in biological macromolecules. Biochem. Biophys. Res. 785 Commun. 95, 1-6.

(12) Piotto, M., Saudek, V., and SklenáR, V. (1992) Gradient-tailored 787 excitation for single-quantum NMR spectroscopy of aqueous 788 solutions. J. Biomol. NMR 2, 661-665.

789

(13) Shaka, A. J., Lee, C. J., and Pines, A. (1988) Iterative schemes 790 for bilinear operators; application to spin decoupling. J. Magn. Reson. 791 77, 274-293.

(14) Delaglio, F., Grzesiek, S., Vuister, G. W., Zhu, G., Pfeifer, J., and 793 Bax, A. D. (1995) NMRPipe: a multidimensional spectral processing 794 system based on UNIX pipes. J. Biomol. NMR 6, 277-293. 795 (15) Goddard, T. D., and Kneller, D. G. (2004) SPARKY 3, 796 University of California, San Francisco.

(16) Wuthrich, K. (1986) NMR of proteins and nucleic acids, Wiley, 798 New York.

(17) Schwieters, C. D., Kuszewski, J. J., Tjandra, N., and Marius 800 Clore, G. (2003) The Xplor-NIH NMR molecular structure 801 determination package. J. Magn. Reson. 160, 65-73.

(18) Sreerama, N., and Woody, R. W. (2004) On the analysis of 803 membrane protein circular dichroism spectra. Protein Sci. 13, 100-112. 804

(19) Rance, M., and Byrd, R. A. (1983) Obtaining High-Fidelity 805 Spin-1/2 Powder Spectra in Anisotropic Media: Phase-Cycled Hahn 806 Echo Spectroscopy. J. Magn. Reson. 52, 221-240.

(20) Davis, J. H., Jeffrey, K. R., Bloom, M., Valic, M. I., and Higgs, T. 808 P. (1976) Quadrupolar Echo Deuteron Magnetic Resonance Spec- 809 
810 troscopy in Ordered Hydrocarbon Chains. Chem. Phys. Lett. 42, 390811394.

812 (21) Seelig, J. (1977) Deuterium magnetic resonance: theory and 813 application to lipid membranes. Q. Rev. Biophys. 10, 353-418.

814 (22) Davis, J. H. (1983) The description of membrane lipid 815 conformation, order and dynamics by $2 \mathrm{H}$-NMR. Biochim. Biophys. 816 Acta, Rev. Biomembr. 737, 117-171.

817 (23) Salnikov, E., Bertani, P., Raap, J., and Bechinger, B. (2009) 818 Analysis of the amide (15) N chemical shift tensor of the C(alpha) 819 tetrasubstituted constituent of membrane-active peptaibols, the alpha820 aminoisobutyric acid residue, compared to those of di- and tri821 substituted proteinogenic amino acid residues. J. Biomol. NMR 45, 822 373-387.

823 (24) Olivieri, C., Buonocore, F., Picchietti, S., Taddei, A. R., Bernini, 824 C., Scapigliati, G., Dicke, A. A., Vostrikov, V. V., Veglia, G., and 825 Porcelli, F. (2015) Structure and membrane interactions of 826 chionodracine, a piscidin-like antimicrobial peptide from the icefish 827 Chionodraco hamatus. Biochim. Biophys. Acta, Biomembr. 1848, 12858281293.

829 (25) Porcelli, F., Verardi, R., Shi, L., Henzler-Wildman, K. A., 830 Ramamoorthy, A., and Veglia, G. (2008) NMR structure of the 831 cathelicidin-derived human antimicrobial peptide LL-37 in dodecyl832 phosphocholine micelles. Biochemistry 47, 5565-5572.

833 (26) Wishart, D. S., Sykes, B. D., and Richards, F. M. (1992) The 834 chemical shift index: a fast and simple method for the assignment of 835 protein secondary structure through NMR spectroscopy. Biochemistry 836 31, 1647-1651.

837 (27) Bechinger, B., Resende, J. M., and Aisenbrey, C. (2011) The 838 structural and topological analysis of membrane-associated polypep839 tides by oriented solid-state NMR spectroscopy: Established concepts 840 and novel developments. Biophys. Chem. 153, 115-125.

841 (28) Bechinger, B., and Salnikov, E. S. (2012) The membrane 842 interactions of antimicrobial peptides revealed by solid-state NMR 843 spectroscopy. Chem. Phys. Lipids 165, 282-301.

844 (29) Kim, C., Spano, J., Park, E. K., and Wi, S. (2009) Evidence of 845 pores and thinned lipid bilayers induced in oriented lipid membranes 846 interacting with the antimicrobial peptides, magainin-2 and aurein-3.3. 847 Biochim. Biophys. Acta, Biomembr. 1788, 1482-1496.

848 (30) Hallock, K. J., Lee, D. K., Omnaas, J., Mosberg, H. I., and 849 Ramamoorthy, A. (2002) Membrane composition determines 850 pardaxin's mechanism of lipid bilayer disruption. Biophys. J. 83, 851 1004-1013.

852 (31) Resende, J. M., Verly, R. M., Aisenbrey, C., Cesar, A., Bertani, P., 853 Pilo-Veloso, D., and Bechinger, B. (2014) Membrane interactions of 854 Phylloseptin-1, -2 , and -3 peptides by oriented solid-state NMR 855 spectroscopy. Biophys. J. 107, 901-911.

856 (32) Salnikov, E., Aisenbrey, C., Balandin, S. V., Zhmak, M. N., 857 Ovchinnikova, A. Y., and Bechinger, B. (2011) Structure and 858 alignment of the membrane-associated antimicrobial peptide arenicin 859 by oriented solid-state NMR spectroscopy. Biochemistry 50, 37848603795

861 (33) Yamaguchi, S., Hong, T., Waring, A., Lehrer, R. I., and Hong, M. 862 (2002) Solid-state NMR investigations of peptide-lipid interaction and 863 orientation of a beta-sheet antimicrobial peptide, protegrin. Bio864 chemistry 41, 9852-9862.

865 (34) Bechinger, B., and Sizun, C. (2003) Alignment and structural 866 analysis of membrane polypeptides by $15 \mathrm{~N}$ and $31 \mathrm{P}$ solid-state NMR 867 spectroscopy. Concepts Magn. Reson. 18A, 130-145.

868 (35) Aisenbrey, C., and Bechinger, B. (2004) Tilt and rotational pitch 869 angles of membrane-inserted polypeptides from combined $15 \mathrm{~N}$ and $8702 \mathrm{H}$ solid-state NMR spectroscopy. Biochemistry 43, 10502-10512.

871 (36) Sanders, C. R., 2nd, and Landis, G. C. (1995) Reconstitution of 872 membrane proteins into lipid-rich bilayered mixed micelles for NMR 873 studies. Biochemistry 34, 4030-4040.

874 (37) Sanders, C. R., and Prosser, R. S. (1998) Bicelles - A model 875 membrane system for all seasons. Structure 6, 1227-1234.

876 (38) Seelig, J. (1978) 31P nuclear magnetic resonance and the head 877 group structure of phospholipids in membranes. Biochim. Biophys. 878 Acta, Rev. Biomembr. 515, 105-140.
(39) Yeagle, P. L. (1990) Phosphorus NMR of Membranes. In 879 Biological Magnetic Resonance, pp 1-54, Plenum Press, New York. 880 (40) Prosser, R. S., Hwang, J. S., and Vold, R. R. (1998) Magnetically 881 aligned phospholipid bilayers with positive ordering: a new model 882 membrane system. Biophys. J. 74, 2405-2418.

883

(41) Tan, A., Ziegler, A., Steinbauer, B., and Seelig, J. (2002) 884 Thermodynamics of sodium dodecyl sulfate partitioning into lipid 885 membranes. Biophys. J. 83, 1547-1556.

(42) Aisenbrey, C., and Bechinger, B. (2004) Investigations of 887 peptide rotational diffusion in aligned membranes by $2 \mathrm{H}$ and $15 \mathrm{~N} 888$ solid-state NMR spectroscopy. J. Am. Chem. Soc. 126, 16676-16683. 889

(43) Salnikov, E. S., Mason, A. J., and Bechinger, B. (2009) 890 Membrane order perturbation in the presence of antimicrobial 891 peptides by $2 \mathrm{H}$ solid-state NMR spectroscopy. Biochimie 91, 734- 892 743.

893

(44) Wieprecht, T., Beyermann, M., and Seelig, J. (1999) Binding of 894 antibacterial magainin peptides to electrically neutral membranes: 895 Thermodynamics and structure. Biochemistry 38, 10377-10378. 896

(45) Bechinger, B. (2015) The SMART model: Soft Membranes 897 Adapt and Respond, also Transiently, to external stimuli. J. Pept. Sci. 898 $21,346-355$.

899

(46) Lauterwein, J., Bosch, C., Brown, L. R., and Wüthrich, K. (1979) 900 Physicochemical studies of the protein-lipid interactions in melittin- 901 containing micelles. Biochim. Biophys. Acta, Biomembr. 556, 244-264. 902

(47) Mani, R., Cady, S. D., Tang, M., Waring, A. J., Lehrer, R. I., and 903 Hong, M. (2006) Membrane-dependent oligomeric structure and pore 904 formation of a beta-hairpin antimicrobial peptide in lipid bilayers from 905 solid-state NMR. Proc. Natl. Acad. Sci. U. S. A. 103, 16242-16247. 906

(48) Sugawara, M., Resende, J. M., Moraes, C. M., Marquette, A., 907 Chich, J. F., Metz-Boutigue, M. H., and Bechinger, B. (2010) Structure 908 and interactions in membranes of human and bovine Catestatin by 909 solution and solid-state NMR spectroscopy. FASEB J. 24, 1737-1746. 910 (49) Jean-Francois, F., Castano, S., Desbat, B., Odaert, B., Roux, M., 911 Metz-Boutigue, M. H., and Dufourc, E. J. (2008) Aggregation of 912 cateslytin beta-sheets on negatively charged lipids promotes rigid 913 membrane domains. A new mode of action for antimicrobial peptides? 914 Biochemistry 47, 6394-6402.

(50) Lai, A. L., Moorthy, A. E., Li, Y., and Tamm, L. K. (2012) 916 Fusion activity of HIV gp41 fusion domain is related to its secondary 917 structure and depth of membrane insertion in a cholesterol-dependent 918 fashion. J. Mol. Biol. 418, 3-15.

(51) Shai, Y. (2002) Mode of action of membrane active 920 antimicrobial peptides. Biopolymers 66, 236-248.

921

(52) Mason, A. J., Martinez, A., Glaubitz, C., Danos, O., Kichler, A., 922 and Bechinger, B. (2006) The antibiotic and DNA-transfecting peptide 923 LAH4 selectively associates with, and disorders, anionic lipids in mixed 924 membranes. FASEB J. 20, 320-322.

(53) Matsuzaki, K., Nakamura, A., Murase, O., Sugishita, K., Fujii, N., 926 and Miyajima, K. (1997) Modulation of magainin 2-lipid bilayer 927 interactions by peptide charge. Biochemistry 36, 2104-2111.

928

(54) Wenk, M., and Seelig, J. (1998) Magainin 2 amide interaction 929 with lipid membranes: Calorimetric detection of peptide binding and 930 pore formation. Biochemistry 37, 3909-3916.
931 